\title{
Exhaled carbon monoxide in lung disease
}

\section{To the Editor:}

We read with interest the paper by ZETTERQUIST et al. [1] in which the levels of exhaled nitric oxide (NO) and carbon monoxide (CO) were measured in a group of asthmatic and cystic fibrosis $(\mathrm{CF})$ patients using two different methods. A new fast-response nondisperse infrared (NDIR) $\mathrm{CO}$ analyser was used alongside the old electrochemical method and the results obtained with the two methods were compared.

Surprisingly, contrary to what has previously been shown by our own and other groups [2-6], as shown by both methods, the levels of exhaled $\mathrm{CO}$ were found to be similar in a group of asthmatic patients and patients with $\mathrm{CF}$ compared with normal subjects. The authors conclude that exhaled $\mathrm{CO}$ is not a marker of airway inflammation and may derive predominantly from the alveoli, as its exhaled concentrations are not flow-dependent and increase after a breath-hold.

Even though we previously acknowledged that the measurement of exhaled $\mathrm{CO}$ may be of more interest in patients with severe asthma compared to those with the mild form of the disease [7, 8], we feel that the measurement of exhaled $\mathrm{CO}$ maybe useful in $\mathrm{CF}$ patients $[5,6,8]$. We suggest that the discrepancies found may be mainly attributed to different techniques and, ultimately, different methods.

First, ZetTERQuist et al. [1] used the basic Bedfont analyser for the measurement of $\mathrm{CO}$. However, in our previously published studies by us a modified version of the Bedfont analyser was used. In this altered version, the exhalation flow rate was standardised and controlled, and a resistance was added to the exhalation flow to produce enough mouth pressure to close the soft palate allowing the separation of nasal air from exhaled air. Besides controlling these parameters, contrary to what is stated in this paper, we did connect the analyser to a computer and the exhaled $\mathrm{CO}$ traces could be studied point by point and in relation to exhaled volumes.

Secondly, in our studies, the exhalation manoeuvre was different from that used in the paper by ZetTerquist et al [1]. We used a single-breath technique without breath-hold. We agree with the authors that breath-hold increases exhaled $\mathrm{CO}$ levels, but in addition, this may also eliminate the bronchial contribution to the total production of $\mathrm{CO}$, which would be biased towards the alveolar component because of alveolar CO diffusion in the bronchial space during the time of breath-hold. This may explain the similar levels of exhaled $\mathrm{CO}$ in the studied groups compared to normal subjects.

Thirdly, in this paper, the contamination of exhaled $\mathrm{CO}$ with ambient $\mathrm{CO}$ was taken into account only in the NDIR method, in which the patients were asked to breathe $\mathrm{CO}$ (and NO)-free air. We have previously shown that exhaled $\mathrm{CO}$ may be affected by ambient $\mathrm{CO}$ and that this influence may be reduced by subtracting ambient $\mathrm{CO}$ from exhaled $\mathrm{CO}$ [6]. Unfortunately, in this study, this was not considered when analysing the levels of $\mathrm{CO}$ obtained with the Bedfont analyser.

In conclusion, the authors of the paper compared the results obtained with two different methods and exhalation techniques. The effect of ambient contamination and breath-hold were not taken into account. Both these variables and the use of different exhalation techniques may explain the discrepancy in the data obtained by ZETTERQUIST et al. [1] and the other investigators in this area. Using fast analysers like the nondisperse infrared analyser may not be beneficial by itself if the exhalation technique is not standardised. Furthermore, comparisons of the data obtained by other numerous groups may only be possible if the same technique and methods are used.

\section{P. Paredi, S.A. Kharitonov, P.J. Barnes}

Dept of Thoracic Medicine, National Heart and Lung Institute, Imperial College School of Science, Technology and Medicine, London, UK.

\section{References}

1. Zetterquist W, Marteus H, Johannesson M, et al. Exhaled carbon monoxide is not elevated in patients with asthma or cystic fibrosis. Eur Respir $J$ 2002; 20: 92-99.

2. Zayasu K, Sekizawa K, Okinaga S, Yamaya M, Ohrui $\mathrm{T}$, Sasaki H. Increased carbon monoxide in exhaled air of asthmatic patients. Am J Respir Crit Care Med 1997; 156: 1140-1143.

3. Horvath I, Donnelly LE, Kiss A, Paredi P, Kharitonov SA, Barnes PJ. Raised levels of exhaled carbon monoxide are associated with an increased expression of heme oxygenase-1 in airway macrophages in asthma: a new marker of oxidative stress. Thorax 1998; 53: 668-672.

4. Yamara M, Sekizawa K, Ishizuka S, Monma M, Sasaki H. Exhaled carbon monoxide levels during treatment of acute asthma. Eur Respir J 1999; 13: 757-760.

5. Paredi P, Shah PL, Montuschi P, et al. Increased carbon monoxide in exhaled air of patients with cystic fibrosis. Thorax 1999; 54: 917-920.

6. Antuni JD, Kharitonov SA, Hughes D, Hodson ME, Barnes PJ. Increase in exhaled carbon monoxide during exacerbations of cystic fibrosis. Thorax 2000; 55: $138-142$

7. Stirling RG, Lim S, Kharitonov SA, Chung KF, Barnes PJ. Exhaled breath carbon monoxide (CO) is minimally elevated in severe but not mild atopic asthma. Am J Respir Crit Care Med 2000; 161: A922.

8. Kharitonov SA, Barnes PJ. Exhaled markers of pulmonary disease. Am J Respir Crit Care Med 2001; 163: 1693-1722.

From the authors:

We appreciate the interest P. Paredi and colleagues have shown in our article. In their letter, they describe 